\title{
Alleviation of Liver Dysfunction, Oxidative Stress and Inflammation Underlies the Protective Effect of Ferulic Acid in Methotrexate-Induced Hepatotoxicity
}

This article was published in the following Dove Press journal:

Drug Design, Development and Therapy

\author{
Mozhdeh Roghani' \\ Heibatullah Kalantari ${ }^{1,2}$ \\ Mohammad Javad Khodayar (iD) ${ }^{1,2}$ \\ Layasadat Khorsandi ${ }^{3}$ \\ Mojtaba Kalantar ${ }^{4}$ \\ Mehdi Goudarzi ${ }^{5}$ \\ Hadi Kalantar (iD ${ }^{1,2}$ \\ 'Toxicology Research Center, Ahvaz \\ Jundishapur University of Medical \\ Sciences, Ahvaz, Iran; ${ }^{2}$ Department of \\ Toxicology, Faculty of Pharmacy, Ahvaz \\ Jundishapur University of Medical \\ Sciences, Ahvaz, Iran; ${ }^{3}$ Cellular and \\ Molecular Research Center, Department \\ of Anatomical Sciences, Ahvaz \\ Jundishapur University of Medical \\ Sciences, Ahvaz, Iran; ${ }^{4}$ Student Research \\ Committee, Shoushtar University of \\ Medical Sciences, Shoushtar, Iran; \\ ${ }^{5}$ Medicinal Plant Research Center, Ahvaz \\ Jundishapur University of Medical \\ Sciences, Ahvaz, Iran
}

Introduction: In multiple studies, involvement of oxidative stress in the pathogenesis of methotrexate (MTX)-mediated liver damage has been confirmed. Use of many drugs has been examined experimentally in order to prevent or diminish oxidative stress. However, no study has yet examined the effects of ferulic acid (FA) on MTX-induced liver damage. This study aimed at evaluating the effects of FA on protection against liver damage induced by MTX in mice.

Materials and Methods: In this the mice were divided into five groups in a random manner: I) control; II) MTX (20 mg/kg); III and IV) FA (50 and $100 \mathrm{mg} / \mathrm{kg}$ ) + MTX; and V) FA $(100 \mathrm{mg} / \mathrm{kg})$, and we measured serum factors, oxidative stress and inflammatory factors. Results: In the MTX group, accumulation of inflammatory cells, accumulation of red blood cell (RBC), and nuclear pyknosis (NP) were detected in the liver. In line with the histological data, the levels of nitric oxide (NO), malondialdehyde (MDA), interleukin-6 (IL-6), and tumor necrosis factor- $\alpha$ increased (TNF- $\alpha$ ), whereas the reduced glutathione (GSH), catalase (CAT), total antioxidant capacity (TAC), superoxide dismutase (SOD), and glutathione peroxidase $(\mathrm{GPx})$ content reduced in the MTX group. However, FA ameliorated these hazardous effects in the antioxidant and anti-inflammatory systems in MTX-treated groups. Conclusion: Based on our findings, oxidative stress impairment and MTX-induced liver damage were ameliorated following FA pretreatment at both histological and biochemical levels. Therefore, FA can be effectively used in abrogation of MTX-induced toxicity.

Keywords: methotrexate, oxidative damage, inflammation, ferulic acid, mice

\section{Introduction}

Drug-induced damage to the liver can be considered a challenging problem, complicating the course of drug therapy and limiting its effectiveness. ${ }^{1}$ Methotrexate (MTX), which is a folic acid antagonist, is recognized as a common anticancer drug. Nevertheless, the cytotoxic effects of MTX not only affect tumor cells, but also influence vital organs. Hepatotoxicity is a major type of toxicity associated with MTX chemotherapy. ${ }^{2,3}$ The prevalence of MTX-induced liver cirrhosis and fibrosis may reach up to $26 \%$ and $50 \%$ in patients, respectively. ${ }^{4}$ According to several studies, oxidative stress contributes to the pathogenesis of MTX-induced damage in multiple organs, particularly the liver. ${ }^{5-7}$

It is known that reactive oxygen species (ROS) contribute to cell apoptosis. ${ }^{8}$ Generally, glutathione (GSH), as a major cytosolic antioxidant, uses nicotinamide adenine dinucleotide phosphate (NADPH). ${ }^{9}$ It has been reported that MTX inhibits nicotinamide adenine dinucleotide phosphate (NADP)-malic enzymes and
Department of Toxicology, Faculty of

Pharmacy and Toxicology Research

Center, Ahvaz Jundishapur University of

Medical Sciences, Ahvaz, Iran

Tel/Fax +98-613738378

Email Kalantar-h@ajums.ac.ir 
cytosolic NADP-dependent dehydrogenases. MTX, by inhibition of pentose cycle enzymes, reduces NADPH availability in cells. Therefore, any failure in the antioxidant defense system can increase cell sensitivity to ROSmediated damage. ${ }^{10}$ It has been also reported that MTX can cause damage to the liver by increasing the level of proinflammatory cytokines. ${ }^{11}$ Therefore, finding an adjuvant hepatoprotective compound is essential for the safe application of this immunosuppressant anticancer drug. Substantial evidence confirms the strong antioxidant characteristics of flavonoid components in vitro.

Ferulic acid (FA), as a phenolic compound, is formed during tyrosine and phenylalanine metabolism and is mostly found in wheat, rice, barely, banana, tomato, citrus fruits, and vegetables. ${ }^{12}$ FA, which is recognized as a strong membrane antioxidant, seems to be effective against skin cancer, influenza, muscle wasting, and fatigue. ${ }^{13}$ Furthermore, FA exerts many pharmacological effects, including anti-nociceptive, anti-inflammatory, antitumor, anti-diabetic, anti-hyperlipidemic, neuroprotective and anti-hypertensive activities. ${ }^{14-19}$

FA, given its extended side chain and phenolic nucleus, can form resonance-stabilized phenoxy radicals, which are responsible for the free radical-scavenging properties. ${ }^{20}$ FA scavenges both reactive nitrogen species (RNS) and ROS through its free radical scavenging activities. ${ }^{21,22}$ The antioxidant activity of FA, as well as its protective effects against Alzheimer's disease, ultraviolet (UV) radiation, and cardiovascular disease, has been established. ${ }^{23}$

Recently, major attention has been paid to phenolic acids for the prevention of various diseases, due to their antioxidant properties. In this study, we aimed at examining the antioxidant and hepatoprotective effects of FA on hepatotoxicity caused by MTX in mice. According to our literature search, this is the first study on the hepatoprotective role of FA in MTX-mediated liver damage.

\section{Materials and Methods}

\section{Chemicals}

Sigma (USA) provided FA and MTX, while Merck Co. (Germany) supplied all other chemicals and reagents of an analytical grade.

\section{Animals}

The animal house of Ahvaz Jundishapur University of Medical Sciences (AJUMS) provided seven- to eight-week-old male Swiss albino mice (22-25 g) for this study. The animals were given one week for acclimatization in a 12:12 $\mathrm{h}$ light-dark cycle under optimal environmental conditions (moderate humidity, $65 \pm 5 \%$; temperature, $22 \pm 2^{\circ} \mathrm{C}$ ). This study was approved by the Ethics Committee of Ahvaz Jundishapur University of Medical Sciences (IR.AJUMS.ABHC.REC.1397.004) and was conducted in conformity with international laws and policies (EEC Council directives 86/609, OJL 358, 1, December, 12, 1987; NIH Guide for the Care and Use of Laboratory Animals, NIH Publications No. 85-23, 1985).

\section{Study Design}

The mice were divided into five groups in a random manner (seven mice per group):

Control group: receiving oral saline $(10 \mathrm{~mL} / \mathrm{kg}$ of FA vehicle) for seven days, as well as a single injection of $0.9 \%$ saline (MTX vehicle, i.p.) on day six;

MTX group: receiving a single MTX injection $(20 \mathrm{mg} /$ $\mathrm{kg}$, i.p.) on day six;

FA+MTX groups: receiving two oral doses of FA (50, $100 \mathrm{mg} / \mathrm{kg}$, p.o.) once every day for one week, as well as MTX (20 mg/kg, i.p.) on day six; and FA group: receiving only $100 \mathrm{mg} / \mathrm{kg}$ of oral FA (p.o.) for seven consecutive days.

The dosage regime of MTX ${ }^{2,11}$ and $\mathrm{FA}^{24,25}$ is based on previous articles that were added to the methods.

After sacrificing the animals via cervical dislocation on the eighth day, the blood samples were centrifuged for 10 minutes at $3000 \mathrm{rpm}$. The collected serum was kept at $-80^{\circ} \mathrm{C}$ until further analysis. The liver was dissected into two sections. The first section was formalin-fixed for the histopathological analysis, while the second part was used for the biochemical assessment, for which the tissue sections were rinsed in cold normal saline and homogenized in ice-cold potassium phosphate buffer $(0.1 \mathrm{M})$. Two cycles of centrifugation were performed at 600 and $10,000 \mathrm{~g}$ on the final homogenate. The collected supernatant was stored at $-70^{\circ} \mathrm{C}$ to determine the oxidative biomarkers, antioxidant enzymes, and proinflammatory cytokines.

\section{Biochemical Analysis}

The serum alkaline phosphatase (ALP), aspartate aminotransferase (AST), and alanine aminotransferase (ALT) were measured, based on the colorimetric kit protocols (Human, Wiesbaden, Germany).

\section{Protein Measurement}

The method proposed by Lowry et al in $1951^{26}$ was applied to measure the protein concentration, with BSA as the standard. 


\section{Oxidative Stress Markers}

The hepatic malondialdehyde (MDA) content was measured based on the methods described by Uchiyama and Mihara in order to evaluate lipid peroxidation. ${ }^{27}$ The nitric oxide (NO) content was also determined based on a study by Green et al. ${ }^{28}$ Next, the tissue levels of catalase (CAT), total antioxidant capacity (TAC), and reduced glutathione (GSH) were determined according to the methods by Beutler, ${ }^{29} \mathrm{Aebi}^{30}$ and Prieto et $\mathrm{al},{ }^{31}$ respectively. Also, superoxide dismutase (SOD), and glutathione peroxidase (GPx) activities were measured using the method described in the commercial kits (ZellBio Company, Germany).

\section{Measurement of Proinflammatory Cytokines}

Using ELISA kits, the serum tumor necrosis factor- $\alpha$ increased (TNF- $\alpha$ ) and interleukin-6 (IL-6), levels were measured (IBL, Germany; TNF- $\alpha$ catalog number: 27,194; IL-6 catalog number: 53061). The manufacturer's instructions were followed during the measurements, and an ELISA reader was used at $450 \mathrm{~nm}$ to read absorbance.

\section{Histopathological Analysis}

The livers were immediately excised following blood collection and fixed in $10 \%$ formalin. After dehydrating the samples in graded alcohol concentrations, they were paraffin-embedded. Then, sections (4-6 $\mu \mathrm{m})$ were prepared, and haemotoxylin and eosin (H\&E) staining was performed. For the analysis of histological changes, including nuclear pyknosis and accumulation of inflammatory cells and RBCs, six microscopic slides were examined per animal.
The histological properties were classified into four groups: normal, weak, moderate, and intense (0-3); the average value was measured. In addition, the percentage of nuclear pyknosis was also measured. After determining the mean of six fields, the slide was read in a "blind" fashion.

\section{Data Analysis}

For data analysis, one-way ANOVA, as well as Tukey's post hoc test, was used at a significance level of 0.05 . Values are presented as mean \pm SD.

\section{Results}

\section{Biochemical Analysis}

Effect of FA and MTX on AST, ALT, and ALP

The ALT, AST and ALP levels increased significantly in the MTX group versus the control group $(P<0.001)$. In animals receiving $50 \mathrm{mg} / \mathrm{kg}$ of FA, ALT and AST, but not ALP, significantly reduced compared with the MTX group $(P<$ 0.05). In mice receiving $100 \mathrm{mg} / \mathrm{kg}$ of FA, ALT, AST and ALP levels decreased significantly versus the MTX group $(P<0.001, P<0.01$, and $P<0.05$, respectively). However, the control group was not significantly different from the group receiving a higher dose of FA (Figure 1A-C).

\section{Effect of FA and MTX on Liver MDA and NO Content}

The hepatic levels of MDA and NO increased significantly in the MTX group $(P<0.001)$ versus the control group. Nevertheless, FA pretreatment at 50 and $100 \mathrm{mg} / \mathrm{kg}$ could attenuate MDA in comparison with the MTX group $(P<0.05$ and $P<0.01)$. The findings showed that $100 \mathrm{mg} / \mathrm{kg}$ of FA
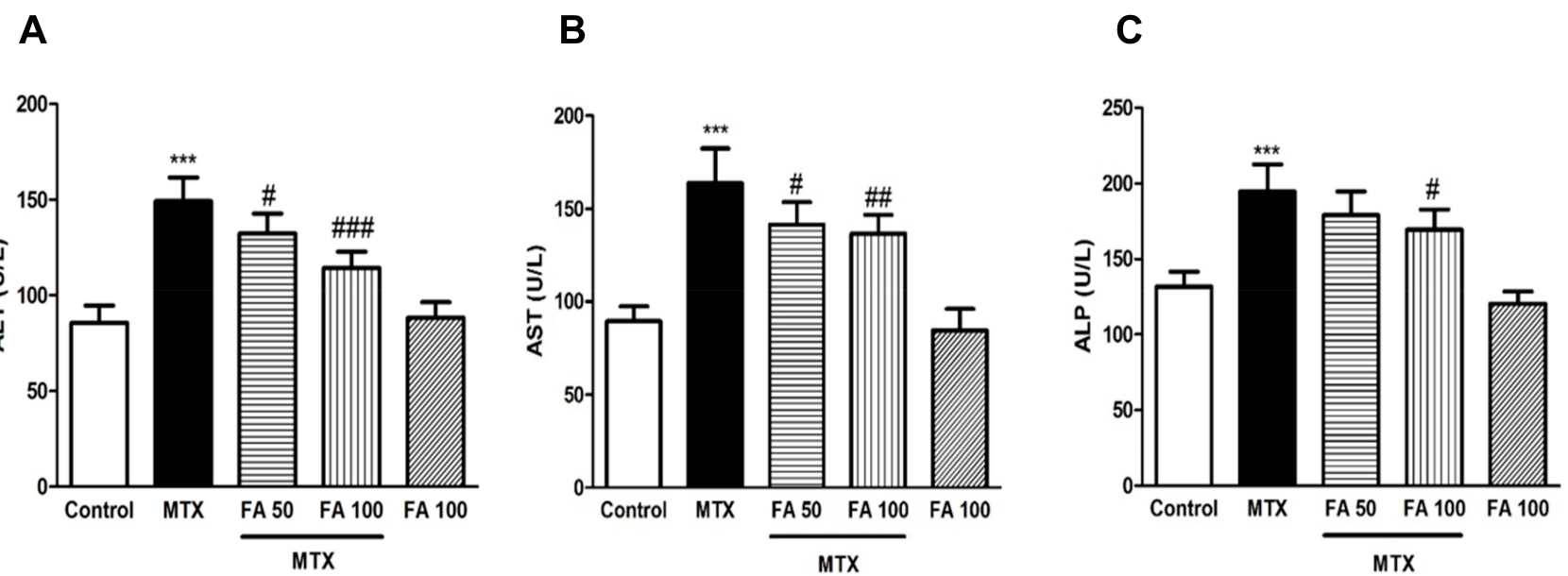

Figure I Effect of ferulic acid (FA) on markers of liver dysfunction in methotrexate (MTX)-induced hepatotoxicity in mice. Values are means \pm SD ( $=7$ ). Data were analyzed by one-way ANOVA followed by Tukey's post hoc test for multiple comparisons. *Significant difference in comparison with the control group (*** $p<0.00 \mathrm{I}$ ). ${ }^{\#}$ Significant difference in comparison with the MTX group $\left({ }^{\#} p<0.05 ;{ }^{\#} p<0.01\right.$ and $\left.{ }^{\#} p<0.00 \mathrm{I}\right)$. 
could significantly reduce the NO content, compared with the MTX group $(P<0.05)$. Nevertheless, higher FA concentrations did not significantly change the MDA or NO content versus the control group (Figure 2A and B).

\section{Effect of FA and MTX on Hepatic TAC and GSH Content}

In MTX-treated mice, GSH and TAC levels decreased significantly, compared with the control group $(P<0.001)$. However, pretreatment with 50 and $100 \mathrm{mg} / \mathrm{kg}$ of FA significantly increased TAC and GSH content, compared with the MTX group $(P<0.05, P<0.01$, and $P<0.001)$. No significant difference was observed between the control group and the group receiving a higher dose of FA (Figure 3A and B).

\section{Effects of FA and MTX on Hepatic CAT, GPx, and SOD}

The GPx, SOD, and CAT levels in the liver reduced in the MTX group versus the control group $(P<0.001, P<0.001$, and $P<0.01$, respectively). Pretreatment with 50 and $100 \mathrm{mg} / \mathrm{kg}$ of FA significantly improved GPx activity in comparison with the MTX group $(P<0.05$ and $P<0.001)$. Furthermore, $100 \mathrm{mg} / \mathrm{kg}$ of FA increased SOD significantly versus the MTX group $(P<0.05)$. CAT activity improved in the liver tissues of FA group to levels not significantly different from the MTX group. Also, no difference was found in theses enzymes between the control group and the group receiving only a higher dose of FA (Figure 4A-C).

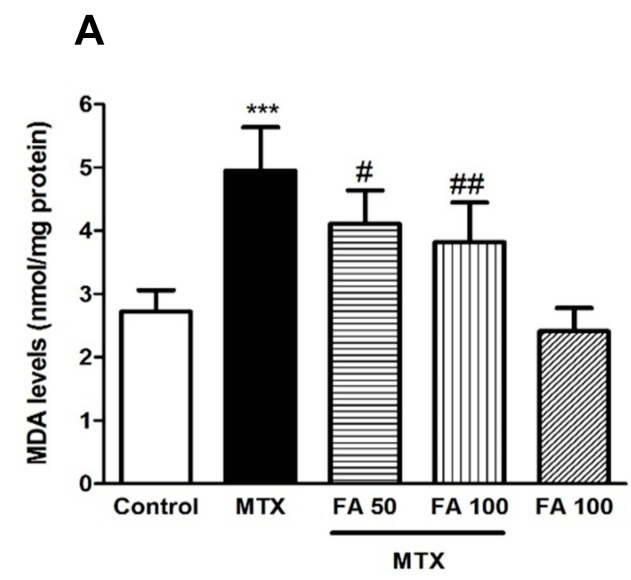

\section{Effect of FA and MTX on Inflammatory Markers}

In comparison with the control group, the hepatic levels of TNF- $\alpha$ and IL-6 significantly increased in the MTX group $(P<0.001)$. This change was reversed by FA pretreatment at 50 and $100 \mathrm{mg} / \mathrm{kg}$, which decreased these parameters, compared with the MTX group $(P<0.05$ and $P<0.001)$. The control group showed no significant difference with the group receiving a higher dose of FA (Figure 5A and B).

\section{Effect of FA on MTX-Mediated Changes in Hepatic Histology}

The control group showed normal hepatocytes. Accumulation of inflammatory cells, accumulation of red blood cells (RBCs), and nuclear pyknosis were reported in the MTX group. FA pretreatment at both doses could reverse the changes, and more normal hepatocytes were produced in the treatment groups. No change occurred in the hepatic architecture at higher doses of FA, which was similar to the control group (Figure 6 and Table 1).

\section{Discussion}

In this experimental study, FA treatment protected against oxidative stress, inflammation, and morphological liver damage due to MTX. Given their negative effects on some organs, including the liver, testis, kidney, and heart, anticancer drugs are not widely used. ${ }^{32-34}$ Several reports have suggested MTX-induced liver toxicity, involving inflammation, apoptosis, and increased AST, ALT, and ALP levels in the serum. ${ }^{35-39}$ In the present study, it was found that MTXtreated mice experienced significant hepatic damages, as

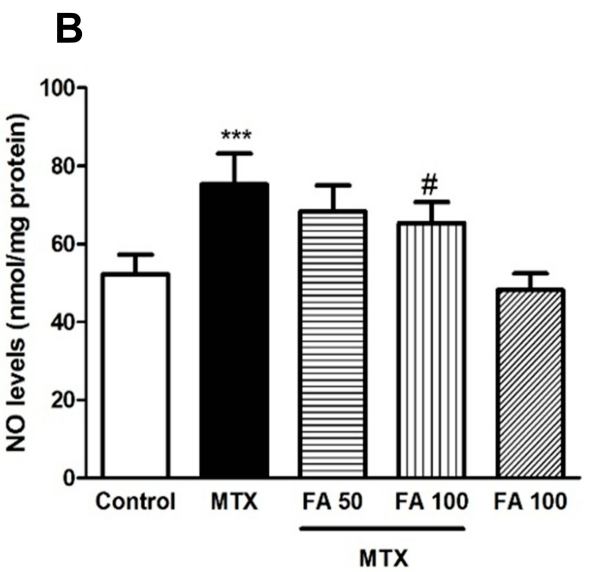

Figure 2 Effect of ferulic acid (FA) on markers of oxidative stress in methotrexate $(M T X)$-induced hepatotoxicity in mice. Values are means \pm SD $(n=7)$. Data were analyzed by one-way ANOVA followed by Tukey's post hoc test for multiple comparisons. *Significant difference in comparison with the control group (*** $p<0.00 \mathrm{I})$. ${ }^{\#}$ Significant difference in comparison with the MTX group $\left({ }^{\#} p<0.05 ;{ }^{\prime \prime} p<0.01\right)$. 
A

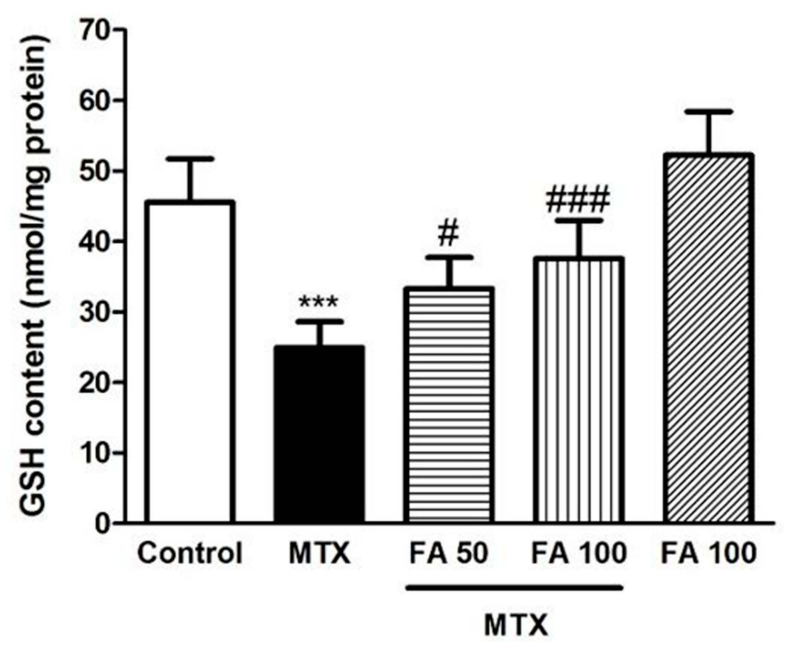

B

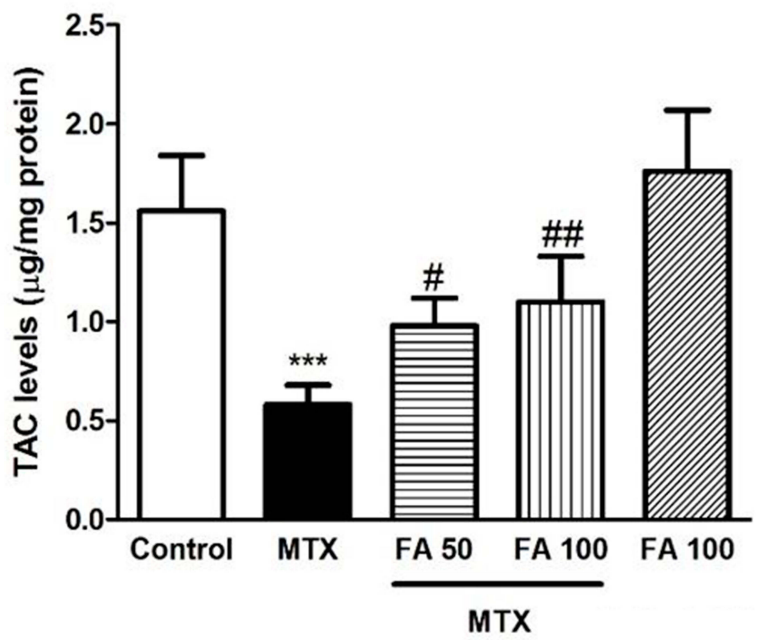

Figure 3 Effect of ferulic acid (FA) on antioxidant factors in methotrexate (MTX)-induced hepatotoxicity in mice. Values are means \pm SD $(n=7)$. Data were analyzed by oneway ANOVA followed by Tukey's post hoc test for multiple comparisons. *Significant difference in comparison with the control group $(* * * p<0.00 \mathrm{I})$. ${ }^{\#}$ Significant difference in comparison with the MTX group $\left({ }^{\#} p<0.05 ;{ }^{\#} p<0.01\right.$ and $\left.{ }^{\# \#} p<0.001\right)$.

confirmed by the significant rise in the serum ALP, AST, and ALT. The histopathological analysis confirmed the biochemical changes, indicating major hepatic damage in the MTX group. The FA pretreatment significantly attenuated biochemical and histopathological changes, suggesting the counteraction of FA with MTX-induced hepatotoxicity.

Several theories have been proposed regarding the mechanisms of MTX-induced toxicity, involving inflammation, oxidative stress, nitrosative stress, and apoptosis. ${ }^{40,41}$ MTX triggers oxidative stress by inhibiting the synthesis of NADP, which maintains reduced GSH. Moreover, it leads to nitrative stress by increasing the concentration of TNF- $\alpha$, which in turn improves inducible nitric oxide synthase (iNOS) expression, as well as
NO and Cyclic guanosine monophosphate (cGMP) production. $^{42}$ Reaction of these highly reactive species with biological macromolecules is associated with the production of lipid peroxides, cellular dysfunction, membrane degradation, and formation of inactivating proteins and mutating deoxyribonucleic acid (DNA). ${ }^{10,43}$

The present study showed significant changes in the oxidant/antioxidant balance by MTX. Based on the findings, MDA content in the MTX group was significantly higher than the control group. MDA, a stable metabolite, is widely used as a marker of oxidative stress. ${ }^{44}$ Lipid peroxidation, caused by oxygen free radicals, may be a major cause of cell membrane damage, as well as MTX-mediated tissue damage. ${ }^{45}$
A

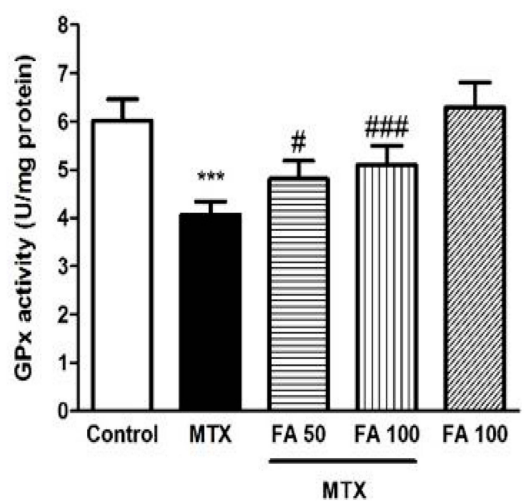

B

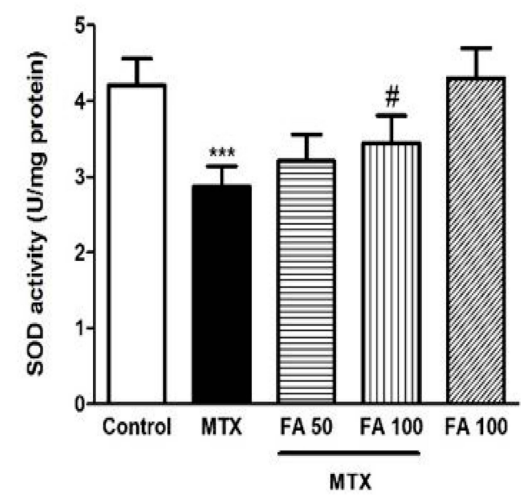

C

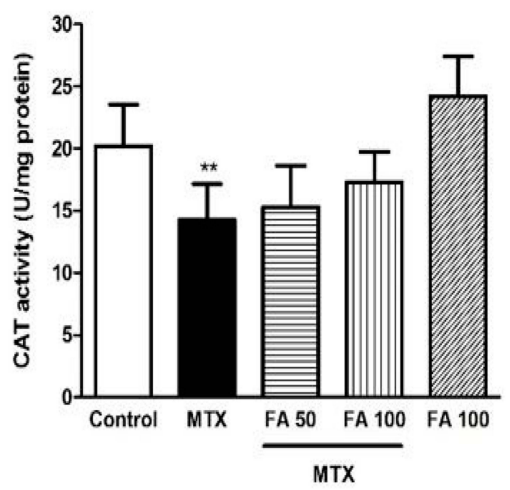

Figure 4 Effect of ferulic acid (FA) on antioxidant enzymes in methotrexate $(M T X)$-induced hepatotoxicity in mice. Values are means \pm SD $(n=7)$. Data were analyzed by one-way ANOVA followed by Tukey's post hoc test for multiple comparisons. *Significant difference in comparison with the control group $(* * p<0.0 \mathrm{I}$ and $* * * p<0.00 \mathrm{I})$. ${ }^{\#}$ Significant difference in comparison with the MTX group $\left({ }^{\#} p<0.05\right.$ and $\left.{ }^{\# \#} p<0.001\right)$. 
A

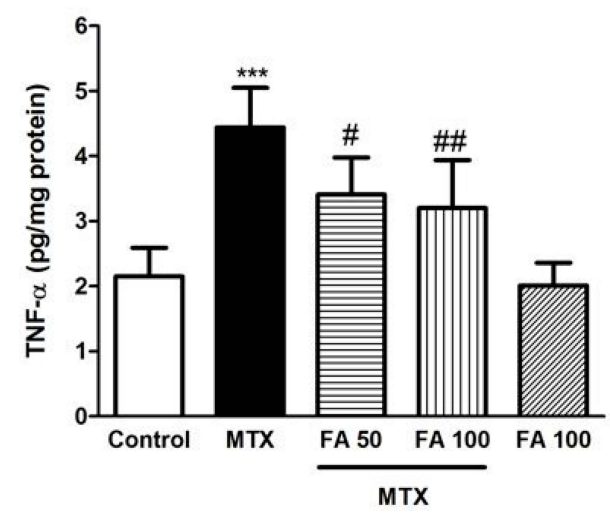

B

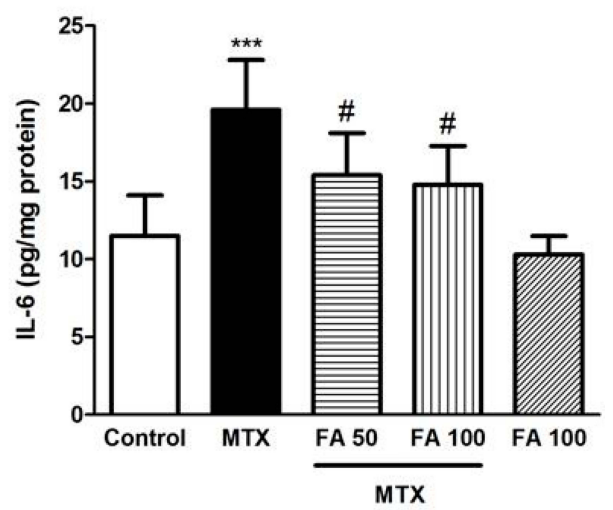

Figure 5 Effect of ferulic acid (FA) inflammatory cytokines in methotrexate (MTX)-induced hepatotoxicity in mice. Values are means \pm SD $(n=7)$. Data were analyzed by one-way ANOVA followed by Tukey's post hoc test for multiple comparisons. *Significant difference in comparison with the control group (*** $p<0.00 \mathrm{I})$. \#Significant difference in comparison with the MTX group $\left({ }^{\#} p<0.05\right.$ and $\left.{ }^{\# \#} p<0.01\right)$.

Similarly, in our study, an increase was found in the NO content of hepatic tissues in the MTX group. Previous studies have confirmed the major involvement of NO in the pathogenesis of MTX toxicity. ${ }^{46,47}$ The high NO content reacts with superoxide anions producing versatile oxidant peroxynitrite and activating nuclear factor kappa
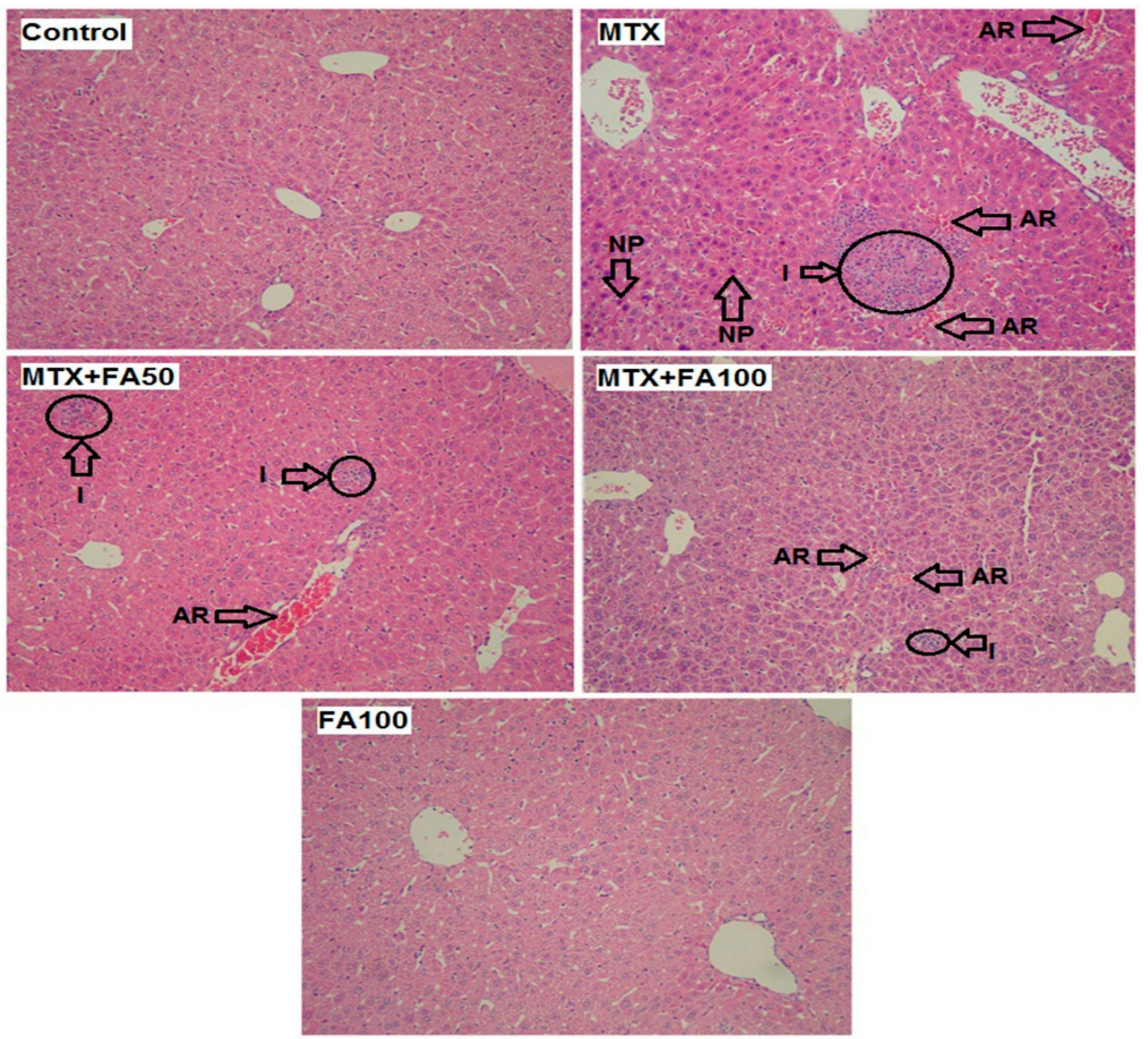

Figure 6 The effect of normal saline, methotrexate, methotrexate + ferulic acid and ferulic acid administration on liver (stained with hematoxylin \& eosin, magnification $X$ 100). (Control), normal saline-treated mice showing normal morphological appearance; (MTX), methotrexate-treated mice showing massive accumulation of RBCs, accumulation of inflammatory cells and nuclear pyknosis; (MTX and FA) methotrexate + ferulic acid at doses (50 and $100 \mathrm{mg} / \mathrm{kg}$ ) treated mice, showing mild hepatic accumulation of RBCs inflammatory cells, (FA) ferulic acid at dose $100 \mathrm{mg} / \mathrm{kg}$ treated mice showing normal morphological appearance similar to the control group. Arrows indicates NP: Nuclear pyknosis and AR: Accumulation of red blood cells, Circles indicates I: Inflammatory cells. 
Table I Effect of Ferulic Acid (FA) on Damage Scores in Liver Tissues Following Methotrexate (MTX)- Induced Hepatotoxicity

\begin{tabular}{|l|l|l|l|l|l|}
\hline \multicolumn{4}{|l|}{ Groups } \\
\hline Histological criteria & Control & MTX & MTX+FA 50 & MTX+FA 100 & FA 100 \\
\hline Accumulation of RBCs & $0.13 \pm 0.00$ & $2.23 \pm 0.24^{* * *}$ & $1.12 \pm 0.16^{\# \#}$ & $0.42 \pm 0.26^{\# \#}$ & $0.11 \pm 0.00$ \\
Accumulation of inflammatory Cells & $0.14 \pm 0.00$ & $1.93 \pm 0.12^{* * *}$ & $0.83 \pm 0.21^{\# \#}$ & $0.34 \pm 0.15^{\# \#}$ & $0.12 \pm 0.00$ \\
Nuclear pyknosis (\%) & $0.00 \pm 0.00$ & $1.49 \pm 0.13^{* * *}$ & $0.1 \pm 0.02^{\ldots}$ & $0.00 \pm 0.00^{\# \#}$ & $0.00 \pm 0.00$ \\
\hline
\end{tabular}

Notes: Values are means \pm SD $(n=7)$. Data were analyzed by one-way ANOVA followed by Tukey's post-hoc test for multiple comparisons. ***Significant with control group, \#涪nificant with MTX Group.

$\mathrm{B}(\mathrm{NF}-\kappa \mathrm{B}){ }^{47}$ In our study, MDA level and NO content significantly decreased following FA pretreatment. Overall, phenolic compounds scavenge free radicals and quench lipid peroxides. According to previous reports, FA, which is approved as a food additive in some countries, is recognized as an effective free radical scavenger, preventing lipid peroxidation. ${ }^{48-50}$

Antioxidant factors, including CAT, SOD, GPx, GSH, and TAC, comprise the first line of defense against oxidative damage. SOD is a sensitive marker of liver damage, as it scavenges superoxide anions to form hydrogen peroxide $\left(\mathrm{H}_{2} \mathrm{O}_{2}\right)$, resulting in the reduction of toxic effects. The most important detoxifying systems for peroxides include $\mathrm{GSH}$ and CAT in hepatic cells. ${ }^{51} \mathrm{GSH}$ and GPx convert $\mathrm{H}_{2} \mathrm{O}_{2}$ and lipid peroxides to nontoxic products through participation in the GSH redox cycle. Therefore, reduction of these factors may produce some negative effects, given the accumulation of $\mathrm{H}_{2} \mathrm{O}_{2}$ and superoxide radicals. ${ }^{52,53}$ Also, TAC represents the total effect of plasma antioxidants. ${ }^{54}$

In our study, MTX reduced the levels of SOD, CAT, GPX, GSH, and TAC of tissues. The feed-back inhibition or oxidative inactivation of enzyme proteins as a result of excess ROS formation may explain the observed decline, ${ }^{55}$ these results are consistent with previous studies. ${ }^{6,10}$ FA could regulate all changes induced by MTX. Also, pretreatment with FA could increase GSH, TAC, SOD, and GPx in an MTX model. These results show that the antioxidant characteristics may be associated with FA-mediated protection against MTX-induced hepatic damage. According to previous studies, FA is a potent antioxidant against carbon tetrachloride, alcohol, bleomycin, acetaminophen, and ironinduced oxidative stress. ${ }^{24,50,56-58}$

Assessment of the effects of MTX on inflammatory cytokines in intoxicated animals is necessary in order to understand the anti-inflammatory effects of FA. Generally, TNF- $\alpha$ and IL- 6 are recognized as proinflammatory cytokines, regulating inflammatory responses. In addition, the release of other cytokines and NO production are promoted, thereby improving oxidative damage. ${ }^{59}$ In the current study, MTX increased the TNF- $\alpha$ and IL-6 levels in liver tissues. According to previous studies, MTX increases IL-6, TNF- $\alpha$, and IL-1 $\beta$ levels. ${ }^{39,47,60,61}$ Also, the inflammatory markers significantly reduced in the FA + MTX groups in the current study. These findings are in line with previous studies, indicating the FA potential to thwart the $\mathrm{CCl}_{4}$-induced release of inflammatory factors. ${ }^{62}$

Based on the histopathological analysis, MTX induced an acute inflammatory reaction, associated with inflammatory cell accumulation, red blood cell (RBC) accumulation, and nuclear pyknosis. Earlier studies explained this reaction by the MTX potential to trigger oxidative and nitrative stress and activate p38 and NF- $\kappa$ B pathways. ${ }^{2,3,63}$ Moreover, our histopathological findings showed the positive effects of FA on MTX-mediated hepatic damage. This finding is consistent with a previous study, suggesting that FA can reduce acetaminophen-related histopathological changes. ${ }^{24}$

\section{Conclusion}

Based on our findings, FA could ameliorate MTXmediated hepatotoxicity. FA, especially at dose $100 \mathrm{mg} /$ $\mathrm{kg}$ could also decrease oxidative stress and inflammation and improve the endogenous antioxidant system to prevent MTX-mediated oxidative damage. Therefore, FA (at dose $100 \mathrm{mg} / \mathrm{kg}$ ) could be a safe option for the prevention of MTX-induced toxicity in humans.

\section{Acknowledgment}

This study is issued from a Pharm.D. Thesis of Mozhdeh Roghani and was financially supported by Toxicology Research Center (Grant number: TRC-9707), funded by the Vice Chancellor of Research, Ahvaz Jundishapur University of Medical Sciences, Ahvaz, Iran.

\section{Disclosure}

All authors declare no conflict of interest related to the present work. 


\section{References}

1. Yuan L, Kaplowitz N. Mechanisms of drug-induced liver injury. Clin Liver Dis. 2013;17(4):507-518. doi:10.1016/j.cld.2013.07.002

2. Kose E, Sapmaz HI, Sarihan E, Vardi N, Turkoz Y, Ekinci N. Beneficial effects of montelukast against methotrexate-induced liver toxicity: a biochemical and histological study. Sci World J. 2012;2012:1-6. doi:10.1100/2012/987508

3. Morsy MA, Ibrahim SA, Amin EF, Kamel MY, Rifaai RA, Hassan MK. Curcumin ameliorates methotrexate-induced nephrotoxicity in rats. $A d v$ Pharmacol Sci. 2013;2013. doi:10.1155/2013/387071

4. Yeo CM, Chong VH, Earnest A, Yang WL. Prevalence and risk factors of methotrexate hepatoxicity in Asian patients with psoriasis. World J Hepatol. 2013;5(5):275. doi:10.4254/wjh.v5.i5.275

5. Şener G, Ekşioğlu-Demiralp E, Cetiner M, et al. L-Carnitine ameliorates methotrexate-induced oxidative organ injury and inhibits leukocyte death. Cell Biol Toxicol. 2006;22(1):47-60. doi:10.1007/s10565-0060025-0

6. Uraz S, Tahan V, Aygun C, et al. Role of ursodeoxycholic acid in prevention of methotrexate-induced liver toxicity. Dig Dis Sci. 2008;53(4):1071-1077. doi:10.1007/s10620-007-9949-3

7. Gao F, Horie T. A synthetic analog of prostaglandin E1 prevents the production of reactive oxygen species in the intestinal mucosa of methotrexate-treated rats. Life Sci. 2002;71(9):1091-1099. doi:10.1016/S0024-3205(02)01795-2

8. Mazur AJ, Nowak D, Mannherz HG, Malicka-Błaszkiewicz M. Methotrexate induces apoptosis in CaSki and NRK cells and influences the organization of their actin cytoskeleton. Eur J Pharmacol. 2009;613(1-3):24-33. doi:10.1016/j.ejphar.2009.04.020

9. Suryawanshi SR. Influence of Various Antioxidants on Extrapyramidal Symptoms of Selected Phenothiazines in Rats. 2010.

10. Jahovic N, Çevik H, Şehirli AÖ, Yeğen BÇ, Şener G. Melatonin prevents methotrexate-induced hepatorenal oxidative injury in rats. $J$ Pineal Res. 2003;34(4):282-287. doi:10.1034/j.1600-079X.2003.00043.x

11. Khalifa MM, Bakr AG, Osman AT. Protective effects of phloridzin against methotrexate-induced liver toxicity in rats. Biomed Pharmacother. 2017;95:529-535. doi:10.1016/j.biopha.2017.08.121

12. Graf E. Antioxidant potential of ferulic acid. Free Radic Biol Med. 1992;13(4):435-448. doi:10.1016/0891-5849(92)90184-I

13. Deuster P, Maier S, Moore V, Paton J, Simmons R, Vawter K. Dietary Supplements and Military Divers: A Synopsis for Undersea Medical Officers. Uniformed Services Univ of The Health Sciences Bethesda Md Dept Of Military; 2004.

14. Ronchetti D, Borghi V, Gaitan G, Herrero JF, Impagnatiello F. NCX 2057, a novel NO-releasing derivative of ferulic acid, suppresses inflammatory and nociceptive responses in in vitro and in vivo models. $B r J$ Pharmacol. 2009;158(2):569-579. doi:10.1111/j.14765381.2009.00324.x

15. Kawabata K, Yamamoto T, Hara A, et al. Modifying effects of ferulic acid on azoxymethane-induced colon carcinogenesis in F344 rats. Cancer Lett. 2000;157(1):15-21. doi:10.1016/S0304-3835(00)00461-4

16. Ramar M, Manikandan B, Raman T, et al. Protective effect of ferulic acid and resveratrol against alloxan-induced diabetes in mice. Eur J Pharmacol. 2012;690(1-3):226-235. doi:10.1016/j.ejphar.2012.05.019

17. Yogeeta SK, Hanumantra RBR, Gnanapragasam A, Subramanian S, Rajakannu S, Devaki T. Attenuation of abnormalities in the lipid metabolism during experimental myocardial infarction induced by isoproterenol in rats: beneficial effect of ferulic acid and ascorbic acid. Basic Clin Pharmacol Toxicol. 2006;98(5):467-472. doi:10.1111/j.1742-7843.2006.pto_335.x

18. Sultana R, Ravagna A, Mohmmad-Abdul H, Calabrese V, Butterfield DA. Ferulic acid ethyl ester protects neurons against amyloid $\beta$-peptide (1-42)-induced oxidative stress and neurotoxicity: relationship to antioxidant activity. $J$ Neurochem. 2005;92 (4):749-758. doi:10.1111/j.1471-4159.2004.02899.x
19. Suzuki A, Kagawa D, Fujii A, Ochiai R, Tokimitsu I, Saito I. Shortand long-term effects of ferulic acid on blood pressure in spontaneously hypertensive rats. Am J Hypertens. 2002;15(4):351-357. doi:10.1016/S0895-7061(01)02337-8

20. Zhao Z, Moghadasian MH. Chemistry, natural sources, dietary intake and pharmacokinetic properties of ferulic acid: a review. Food Chem. 2008;109(4):691-702. doi:10.1016/j.foodchem.2008.02.039

21. Trombino S, Cassano R, Ferrarelli T, Barone E, Picci N, Mancuso C. Trans-ferulic acid-based solid lipid nanoparticles and their antioxidant effect in rat brain microsomes. Colloids Surf B Biointerfaces. 2013;109:273-279. doi:10.1016/j.colsurfb.2013.04.005

22. Barone E, Calabrese V, Mancuso C. Ferulic acid and its therapeutic potential as a hormetin for age-related diseases. Biogerontology. 2009;10(2):97-108. doi:10.1007/s10522-008-9160-8

23. Mancuso C, Santangelo R. Ferulic acid: pharmacological and toxicological aspects. Food Chem Toxicol. 2014;65:185-195. doi:10.1016/j. fct.2013.12.024

24. Krishnan DN, Prasanna N, Sabina EP, Rasool M. Hepatoprotective and antioxidant potential of ferulic acid against acetaminophen-induced liver damage in mice. Comp Clin Path. 2013;22(6):1177-1181. doi:10.1007/ s00580-012-1546-y

25. Yuan J, Ge K, Mu J, et al. Ferulic acid attenuated acetaminophen-induced hepatotoxicity though down-regulating the cytochrome P 2E1 and inhibiting toll-like receptor 4 signaling-mediated inflammation in mice. $\mathrm{Am}$ $J$ Transl Res. 2016;8(10):4205.

26. Lowry OH, Rosebrough NJ, Farr AL, Randall RJ. Protein measurement with the Folin phenol reagent. J Biol Chem. 1951;193:265-275.

27. Uchiyama M, Mihara M. Determination of malonaldehyde precursor in tissues by thiobarbituric acid test. Anal Biochem. 1978;86 (1):271-278. doi:10.1016/0003-2697(78)90342-1

28. Green LC, Wagner DA, Glogowski J, Skipper PL, Wishnok JS, Tannenbaum SR. Analysis of nitrate, nitrite, and [15N] nitrate in biological fluids. Anal Biochem. 1982;126(1):131-138. doi:10.1016/ 0003-2697(82)90118-X

29. Beutler E. Improved method for the determination of blood glutathione. J Lab Clin Med. 1963;61:882-888.

30. Aebi H. [13] Catalase in Vitro. Methods in Enzymology. 105. Elsevier; 1984:121-126.

31. Prieto P, Pineda M, Aguilar M. Spectrophotometric quantitation of antioxidant capacity through the formation of a phosphomolybdenum complex: specific application to the determination of vitamin E. Anal Biochem. 1999;269(2):337-341. doi:10.1006/abio.1999.4019

32. Sawhney P, Giammona CJ, Meistrich ML, Richburg JH. Cisplatininduced long-term failure of spermatogenesis in adult $\mathrm{C} 57 / \mathrm{Bl} / 6 \mathrm{~J}$ mice. J Androl. 2005;26(1):136-145.

33. Ciftci O, Ozdemir I, Vardi N, Gurbuz N. Novel platinum-N-heterocyclic carbene complex is more cardiotoxic than c is-platin in rats. Hum Exp Toxicol. 2011;30(9):1342-1349. doi:10.1177/0960327110390064

34. Ateşşahin A, Şahna E, Türk G, et al. Chemoprotective effect of melatonin against cisplatin-induced testicular toxicity in rats. J Pineal Res. 2006;41(1):21-27. doi:10.1111/j.1600-079X.2006.00327.x

35. Hemeida R, Mohafez O. Curcumin attenuates methotraxate-induced hepatic oxidative damage in rats. $J$ Egypt Natl Canc Inst. 2008;20 (2):141-148.

36. Moghadam AR, Tutunchi S, Namvaran-Abbas-Abad A, et al. Preadministration of turmeric prevents methotrexate-induced liver toxicity and oxidative stress. BMC Complement Altern Med. 2015;15 (1):246. doi:10.1186/s12906-015-0773-6

37. Fiest KM, Sauro KM, Wiebe S, et al. Prevalence and incidence of epilepsy: a systematic review and meta-analysis of international studies. 2017;88(3):296-303.

38. Abdel-Daim MM, Khalifa HA, Abushouk AI, Dkhil MA, Al-Quraishy SA. Diosmin attenuates methotrexate-induced hepatic, renal, and cardiac injury: a biochemical and histopathological study in mice. Oxid Med Cell Longev. 2017;2017:1-10. doi:10.1155/2017/3281670 
39. van Swelm RP, Laarakkers CM, Kooijmans-Otero M, de Jong EM, Masereeuw R, Russel FG. Biomarkers for methotrexate-induced liver injury: urinary protein profiling of psoriasis patients. Toxicol Lett. 2013;221(3):219-224. doi:10.1016/j.toxlet.2013.06.234

40. Çakır T, Özkan E, Dulundu E, et al. Caffeic acid phenethyl ester (CAPE) prevents methotrexate-induced hepatorenal oxidative injury in rats. World J Pharm Res. 2011;63(12):1566-1571. doi:10.1111/ j.2042-7158.2011.01359.x

41. Mukherjee S, Ghosh S, Choudhury S, et al. Pomegranate reverses methotrexate-induced oxidative stress and apoptosis in hepatocytes

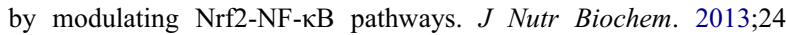
(12):2040-2050. doi:10.1016/j.jnutbio.2013.07.005

42. Kiemer AK, Hartung T, Vollmar AM. cGMP-mediated inhibition of TNF$\alpha$ production by the atrial natriuretic peptide in murine macrophages. J Immunol. 2000;165(1):175-181. doi:10.4049/jimmunol.165.1.175

43. Cetinkaya A, Bulbuloglu E, Kurutas EB, Kantarceken B. $\mathrm{N}$-acetylcysteine ameliorates methotrexate-induced oxidative liver damage in rats. Med Sci Monit. 2006;12(8):BR274-BR8.

44. Sahna E, Parlakpinar H, Cihan OF, Turkoz Y, Acet A. Effects of aminoguanidine against renal ischaemia-reperfusion injury in rats. Cell Biochem Function. 2006;24(2):137-141. doi:10.1002/cbf.1196

45. Çetin A, Kaynar L, Kocyigit I, et al. Role of grape seed extract on methotrexate induced oxidative stress in rat liver. Am J Chin Med (Gard City N Y). 2008;36(05):861-872. doi:10.1142/S0192415X08006302

46. Kalantar M, Kalantari H, Goudarzi M, Khorsandi L, Bakhit S, Kalantar H. Crocin ameliorates methotrexate-induced liver injury via inhibition of oxidative stress and inflammation in rats. Pharmacol Rep. 2019;71:746-752. doi:10.1016/j.pharep.2019.04.004

47. El-Sheikh AA, Morsy MA, Abdalla AM, Hamouda AH, Alhaider IA. Mechanisms of thymoquinone hepatorenal protection in methotrexate-induced toxicity in rats. Mediators Inflamm. 2015;2015:1-12. doi:10.1155/2015/859383

48. Adam A, Crespy V, Levrat-Verny MA, et al. The bioavailability of ferulic acid is governed primarily by the food matrix rather than its metabolism in intestine and liver in rats. $J$ Nutr. 2002;132 (7): 1962-1968. doi:10.1093/jn/132.7.1962

49. Toda S, Kimura M, Ohnishi M. Effects of phenolcarboxylic acids on superoxide anion and lipid peroxidation induced by superoxide anion. Planta Med. 1991;57(01):8-10. doi:10.1055/s-2006-960005

50. Srinivasan M, Rukkumani R, Ram Sudheer A, Menon VP. Ferulic acid, a natural protector against carbon tetrachloride-induced toxicity. Fundam Clin Pharmacol. 2005;19(4):491-496. doi:10.1111/j.14728206.2005.00332.x
51. Solanki Y, Jain S. Hepatoprotective effects of Clitoria ternatea and Vigna mungo against acetaminophen and carbon tetrachloride-induced hepatotoxicity in rats. $J$ Pharmacol Toxicol. 2011;6(1):30-48. doi:10.3923/ jpt.2011.30.48

52. Janbaz KH, Saeed SA, Gilani AH. Protective effect of rutin on paracetamol-and $\mathrm{CCl} 4$-induced hepatotoxicity in rodents. Fitoterapia. 2002;73(7-8):557-563. doi:10.1016/S0367-326X(02) 00217-4

53. Murugesh KS, Channabasappa Yeligar V, Maiti BC, Kumar Maity T. Hepato protective and antioxidant role of Berberis tinctoria Lesch leaves on paracetamol induced hepatic damage in rats. Iran J Pharm Res. 2005;4(1):64.

54. Erel O. A new automated colorimetric method for measuring total oxidant status. Clin Biochem. 2005;38(12):1103-1111. doi:10.1016/j. clinbiochem.2005.08.008

55. Ohta Y, Kongo-Nishimura M, Matsura T, Yamada K, Kitagawa A, Kishikawa T. Melatonin prevents disruption of hepatic reactive oxygen species metabolism in rats treated with carbon tetrachloride. J Pineal Res. 2004;36(1):10-17. doi:10.1046/j.1600-079X.2003.00091.X

56. Rukkumani R, Aruna K, Varma PS, Menon V. Influence of ferulic acid on circulatory prooxidant. J Physiol Paris. 2004;55(3):551-561.

57. Stagos D, Ouris S, Kouretas D. Plant phenolics protect from bleomycin-induced oxidative stress and mutagenicity in Salmonella typhimurium TA102. Anticancer Res. 2004;24(2B):743-746.

58. Zhang Z, Wei T, Hou J, Li G, Yu S, Xin W. Iron-induced oxidative damage and apoptosis in cerebellar granule cells: attenuation by tetramethylpyrazine and ferulic acid. Eur J Pharmacol. 2003;467 (1-3):41-47. doi:10.1016/S0014-2999(03)01597-8

59. Luedde T, Schwabe RF. NF- $\kappa$ B in the liver-linking injury, fibrosis and hepatocellular carcinoma. Nat Rev Gastroenterol Hepatol. 2011;8 (2):108. doi:10.1038/nrgastro.2010.213

60. De S, Kundu S, Chatterjee U, Chattopadhyay S, Chatterjee M. Allylpyrocatechol attenuates methotrexate-induced hepatotoxicity in a collagen-induced model of arthritis. Free Radic Res. 2018;52 (6):698-711. doi:10.1080/10715762.2018.1466391

61. Badr GM. Ameliorative effect of propolis extract on hepatotoxicity induced by methotrexate in mice. Asian J Appl Sci. 2016;4(4).

62. Kim H-Y, Park J, Lee K-H, et al. Ferulic acid protects against carbon tetrachloride-induced liver injury in mice. Toxicology. 2011;282 (3):104-111. doi:10.1016/j.tox.2011.01.017

63. Kim Y-J, Song M, Ryu J-C. Inflammation in methotrexate-induced pulmonary toxicity occurs via the p38 MAPK pathway. Toxicology. 2009;256(3):183-190. doi:10.1016/j.tox.2008.11.016
Drug Design, Development and Therapy

\section{Publish your work in this journal}

Drug Design, Development and Therapy is an international, peerreviewed open-access journal that spans the spectrum of drug design and development through to clinical applications. Clinical outcomes, patient safety, and programs for the development and effective, safe, and sustained use of medicines are a feature of the journal, which has also been accepted for indexing on PubMed Central. The manuscript management system is completely online and includes a very quick and fair peer-review system, which is all easy to use. Visit http://www. dovepress.com/testimonials.php to read real quotes from published authors. 